\title{
Influence of Bonding Condition on Bonding Process Using Ag Metallo-Organic Nanoparticles for High Temperature Lead-Free Packaging
}

\author{
Eiichi Ide*, Akio Hirose and Kojiro F. Kobayashi \\ Department of Manufacturing Science, Graduate School of Engineering, Osaka University, Suita 565-0871, Japan
}

We have proposed a novel bonding process using Ag metallo-organic nanoparticles with the average particle size of $11 \mathrm{~nm}$, which can be the alternative to the current die-attach process using lead-rich high temperature solders. The metallurgical bonding between $\mathrm{Ag}$ and $\mathrm{Cu}$ can be achieved in $\mathrm{Cu}$-to- $\mathrm{Cu}$ joints using the $\mathrm{Ag}$ metallo-organic nanoparticles at temperatures lower than $573 \mathrm{~K}$. Bonding parameters of the $\mathrm{Cu}$-to-Cu joints bondability were examined based on the measurement of the shear strength of the joints and the observation of the fracture surfaces and the cross-sectional microstructures. The joints using the Ag metallo-organic nanoparticles had the joint strength from 10 to $50 \mathrm{MPa}$ depending on bonding conditions. From the results, the bonding conditions providing the joint strength equivalent to those using the lead-rich high melting point solders were proposed.

(Received May 19, 2005; Accepted November 15, 2005; Published January 15, 2006)

Keywords: silver metallo-organic nanoparticles, high temperature solder, lead-free, shear strength

\section{Introduction}

Recently, lead-free solders have been studied because of the harmfulness of lead. However, numerous studies ${ }^{1)}$ on the lead-free solders have been focused on the low to middle melting point solders that are the alternatives to the $\mathrm{Sn}-\mathrm{Pb}$ eutectic solder. On the other hand, an alternative lead-free solder to lead-rich solders used for the die attach in power devices is difficult to be developed. The difficulty arises from the following two requirements on the thermal characteristics: it must have the equivalent bonding temperature to that of current lead-rich solders and it must have the higher solidus temperature than the reflow temperature for the low to middle melting point lead-free solders, such as $\mathrm{Sn}-\mathrm{Ag}$ system solders. The available alloys satisfying both thermal characteristics mentioned above and adequate mechanical properties have not been found, though Shimizu et al. ${ }^{2)}$ have proposed $\mathrm{Zn}-4 \mathrm{Al}-3 \mathrm{Mg}-3.2 \mathrm{Ga}$ and John et al. ${ }^{3)}$ have proposed $\mathrm{Ge}-\mathrm{Doped} \mathrm{Bi}-11 \mathrm{Ag}$ alloy. For such circumstances, we have proposed a novel bonding process using Ag metalloorganic nanoparticles as the alternative lead-free process to the die attach using the lead-rich solder. ${ }^{4}$ )

However, there is a problem in the use of the nanoparticles. That is "self-cohesion" of the nanoparticles. ${ }^{5)}$ It is the problem that each particle gathers by itself, because the surface of the nanoparticle is very active. Therefore, it is necessary to form protective layer on the surface of nanoparticle for the purpose of handling such nanoparticles. Recently, numerous Ag metallo-organic nanoparticles have been developed. The organic shell contained in the $\mathrm{Ag}$ metallo-organic nanoparticles has a function as the passivation layer that prevents the self-cohesion of the nanoparticles. There are mainly two ways to fabricate such Ag metalloorganic nanoparticles. One is physical vapor preparation. ${ }^{6)}$ The other is chemically reduction method. ${ }^{7)}$ In this research, we used the Ag metallo organic nanoparticles fabricated by the chemically reduction method, and the nanoparticles have the thermal characteristic described bellow. As mentioned above, the nanoparticles are covered with the organic shell because of the "self-cohesion" problem, yet we needed to lead out the "self-cohesion", in other words, "active property", when applying them to the bonding process. The decomposition temperature of the organic shell to lead out the activate properties is lower than the melting points of the other lead free solders. Consequently, the bonding by the nanoparticles is available at $573 \mathrm{~K}$, which is lower enough to be applied as the alternative to the current lead rich solder. Moreover, the $\mathrm{Cu}$-to- $\mathrm{Cu}$ joints by the nanoparticles have significantly higher strengths than the joints using the Ag fine particles. The average size of the $\mathrm{Ag}$ fine particle is approximately $100 \mathrm{~nm}$, which is almost 10 times as large as the Ag nanoparticle. In the case of the bonding process by the nanoparticles, the $\mathrm{Cu}$ substrate and the sintered $\mathrm{Ag}$ layer (which is the Ag layer that derives from the agglomerated Ag nanoparticles after the organic shell was removed by heating) are metallurgically bonded, so that the joint is much more substantial, compared to that by Ag fine particles. ${ }^{8)}$ In the electronic field, although research regarding the improvement of the thermal conductivity of conductive adhesives by using the Ag nanoparticle as the filler particles ${ }^{9}$ ) have been reported, there is no research regarding metallurgically bonding using the Ag nanoparticles. Therefore, this is a novel application of nanoparticles. In addition, the sintered Ag layer after bonding is thermally and physically stable because the sintered Ag layer is equivalent to Ag bulk. From this standpoint, this process can be not only the alternative to the lead-rich solder but also a new electronics assembly process. In this paper, the influences of the bonding parameters on the bondability of the $\mathrm{Cu}$-to- $\mathrm{Cu}$ joints using the Ag metallo-organic nanoparticles were examined based on the measurement of the shear strength of the joints, the observation of the fracture surfaces and the cross-sectional microstructures. From the results, the bonding conditions providing the joint strength equivalent to those using the lead-rich high melting point solders were proposed. 


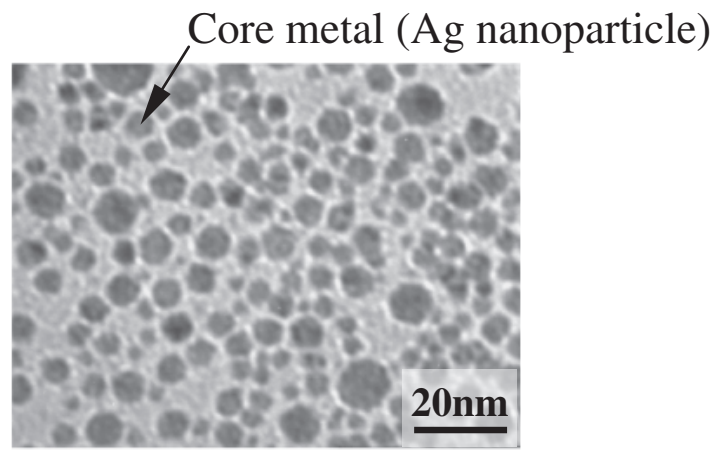

Fig. 1 TEM image of Ag metallo-organic nanoparticles.

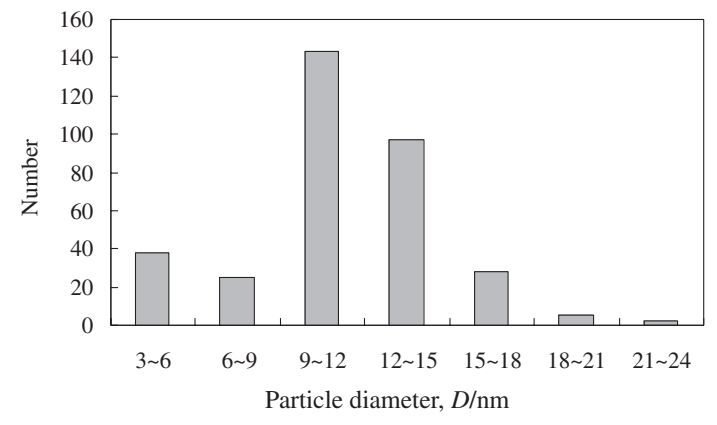

Fig. 2 Distribution of particle size.

\section{Experimental Procedure}

The Ag nanoparticles used in this research are the Ag metallo-organic nanoparticles (hereafter described as Ag nanoparticles) synthesized chemically. The organic shell, which is derived from Myristyl alcohol, has a function as the passivation layer that prevents self-cohesion of the nanoparticles. The image of nanoparticles obtained with a transmission electron microscopy (TEM) is shown in Fig. 1. Figure 2 shows the distribution of the particle. The average size of the $\mathrm{Ag}$ nanoparticles is around $11 \mathrm{~nm}$, and the particles are isolated from each other. The Ag nanoparticle paste was prepared by mixing the nanoparticles with an organic solvent. The $\mathrm{Pb}-5 \mathrm{Sn}$ and $\mathrm{Pb}-10 \mathrm{Sn}$ solder foils (diameter: $5 \mathrm{~mm}$, thickness: $50 \mu \mathrm{m}$ ) were used as reference materials. The shape of the oxygen-free $\mathrm{Cu}$ specimens ${ }^{10)}$ used for the bonding experiment is shown in Fig. 3. The faying surfaces of the specimens were polished with $1 \mu \mathrm{m}$ diamond paste, soaked in dilute hydrochloric acid for $60 \mathrm{~s}$, and then cleaned with distilled water and acetone before bonding. The $\mathrm{Ag}$ nanoparticle paste was supplied on the faying surface of the $\phi 10 \mathrm{~mm} \mathrm{Cu}$ specimen, which was set on the $\phi 5 \mathrm{~mm} \mathrm{Cu}$ specimen. Subsequently, the prepared $\mathrm{Cu}$-to- $\mathrm{Cu}$ disc joint specimens with the Ag nanoparticle paste were bonded with varying bonding temperatures $(533,553$ or $573 \mathrm{~K})$, holding times $(150,300$ or $600 \mathrm{~s})$ and bonding pressures $(1,2.5,5$ or $7.5 \mathrm{MPa}$ ) in an infrared oven. The bonding was carried out in air. The reflow condition for the lead-rich solders is $593 \mathrm{~K}$ $(\mathrm{Pb}-5 \mathrm{Sn})$ or $573 \mathrm{~K}(\mathrm{~Pb}-10 \mathrm{Sn})$ for $160 \mathrm{~s}$ with preheating at $423 \mathrm{~K}$ for $60 \mathrm{~s}$ (with a rosin type flux). The strength of the $\mathrm{Cu}-$ to- $\mathrm{Cu}$ joints was measured with a shear cross head speed of $8.33 \times 10^{-5} \mathrm{~m} / \mathrm{s}$ as shown in Fig. 4. For the observation of

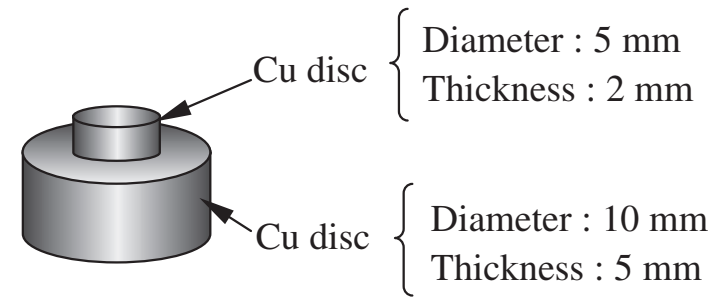

Fig. 3 Shape of specimen.

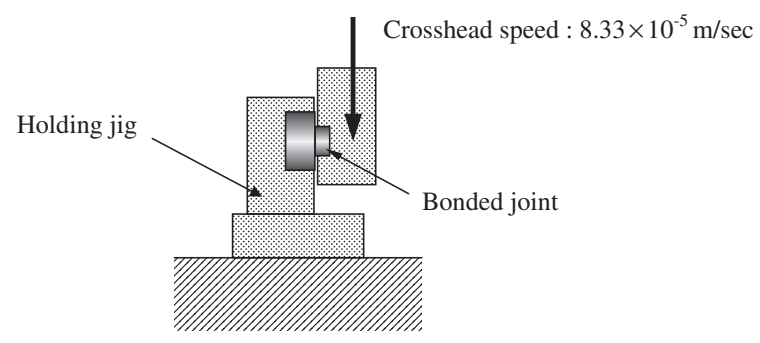

Fig. 4 Illustration of shearing test.

the cross-sectional microstructures, the $\mathrm{Cu}$-to- $\mathrm{Cu}$ joints were metallographically polished and examined with a scanning electron microscope (SEM) equipped with an electron probe micro analyzer (EPMA). The fracture surfaces of the $\mathrm{Cu}$-to$\mathrm{Cu}$ joints using the $\mathrm{Ag}$ nanoparticles were observed with SEM, and the elements of each position of the fracture surfaces were examined with an Energy Dispersion X-ray (EDX) analysis.

\section{Results and Discussion}

\subsection{Influence of bonding parameters on shear strength of Cu-to- $\mathrm{Cu}$ joints}

During the bonding process using the Ag metallo-organic nanoparticles, both the sintering of the Ag nanoparticles and the bonding of the $\mathrm{Ag}$ nanoparticles to the $\mathrm{Cu}$ substrate are performed at the same time. The removal of the organic shell from the Ag nanoparticles led out the activated property of the nanoparticles. It is considered that the increase in the bonding temperature and the holding time urges the removal of the organic shell, and the increase in the bonding pressure contributes to the outgassing of the organic shell. Moreover, these bonding parameters affect the sintering and the bonding phenomena of the Ag nanoparticles after the decomposition of the organic shell. In order to investigate the influence of the bonding parameters on these processes, the $\mathrm{Cu}$-to- $\mathrm{Cu}$ joints were made with various bonding temperatures, holding times and bonding pressures. Figure 5 shows the shear strength of the $\mathrm{Cu}$-to- $\mathrm{Cu}$ disc joints at each bonding temperature with various holding times and bonding pressures.

The joint strength increased only a little with the accumulation of the holding time in this bonding condition, so the increase in the holding time might promote the sintering of the Ag particles. According to the result, the sintering of the $\mathrm{Ag}$ nanoparticles is almost completed by holding for $150 \mathrm{~s}$. On the other hand, the influence of the bonding temperature depended on bonding pressure. Under a lower bonding pressure of $2.5 \mathrm{MPa}$ or less, the increase of the bonding tem- 


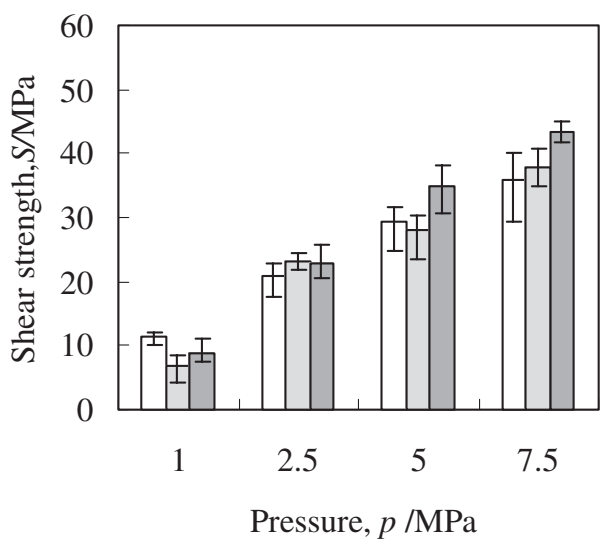

(a) At $533 \mathrm{~K}$

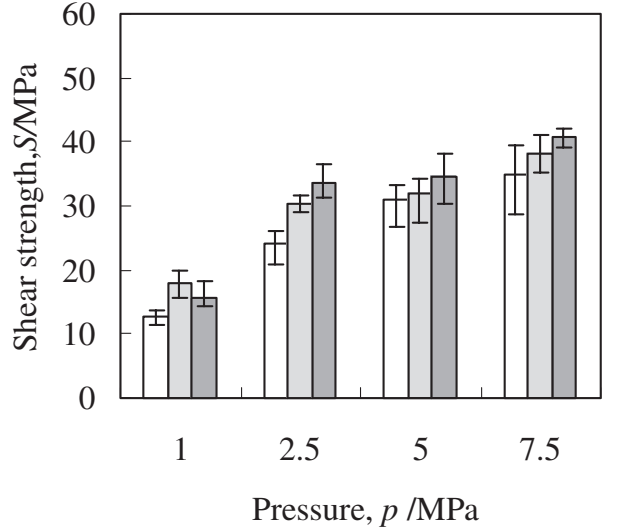

(b) At $553 \mathrm{~K}$

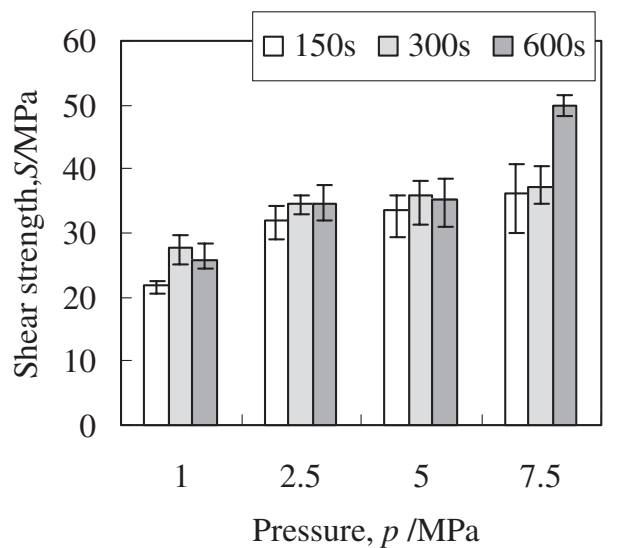

(c) At $573 \mathrm{~K}$

Fig. 5 The shear strength of $\mathrm{Cu}$-to-Cu disc joint made using Ag metallo-organic nanoparticles at each bonding temperature with various holding time and bonding pressures.

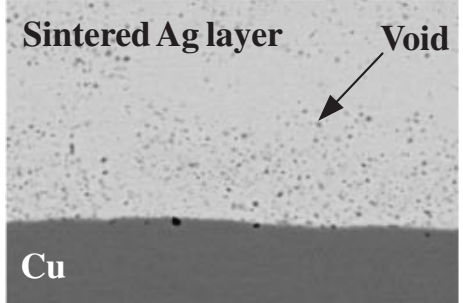

(a) At $533 \mathrm{~K}$

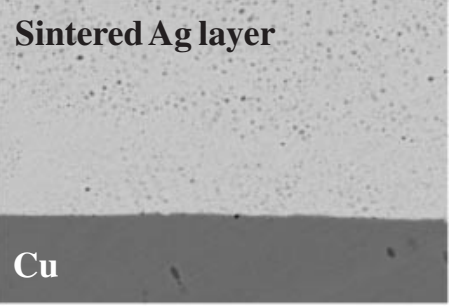

(b) At $553 \mathrm{~K}$

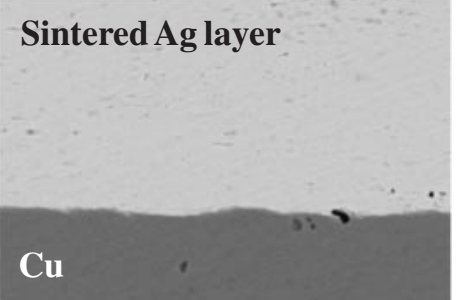

(c) At $573 \mathrm{~K}$

$\underline{5 \mu \mathrm{m}}$

Fig. $6 \mathrm{BE}$ images of $\mathrm{Cu} / \mathrm{Ag}$ interface in the joints bonded at various bonding temperature $\mathrm{f}$ or $300 \mathrm{~s}$ under bonding pressure of $1 \mathrm{MPa}$.

perature considerably raised the joint strength, while under a higher bonding pressure of $5 \mathrm{MPa}$ or more, the joint strength was scarcely affected by the bonding temperature. Finally, the increase in the bonding pressure brought a significant improvement of the joint strength at each bonding temperature. This is probably because the enhancement of the bonding pressure makes the sintered $\mathrm{Ag}$ layer denser and improved the interfacial bonding strength between $\mathrm{Ag}$ and $\mathrm{Cu}$.

\subsection{Influence of bonding parameters on microstructure and fracture morphology of $\mathrm{Cu}$-to- $\mathrm{Cu}$ joints}

In order to examine the relationship between the shear strength and the microstructure of the $\mathrm{Cu}$-to- $\mathrm{Cu}$ joints, their cross-sectional microstructures and fracture surfaces were observed. Reflecting the results in the previous section, the difference in the microstructure and fracture morphology depending on the holding time was not recognized so much.

A significant influence of the bonding pressure on the microstructure of the joints was recognized as shown in Figs. 6 and 7. Under the low pressure conditions as shown in Fig. 6, a number of submicron voids were observed in the sintered Ag layer at each bonding temperature. However, under the high pressure conditions as shown in Fig. 7, the voids were reduced or disappeared, and the sintered Ag layer became denser. Moreover, the change in the fracture mode was recognized as shown in Figs. 8 and 9. The fracture site 


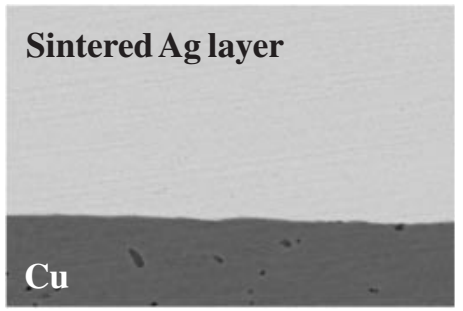

(a) At $533 \mathrm{~K}$

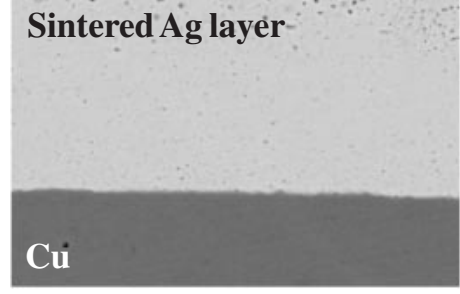

(b) At $553 \mathrm{~K}$

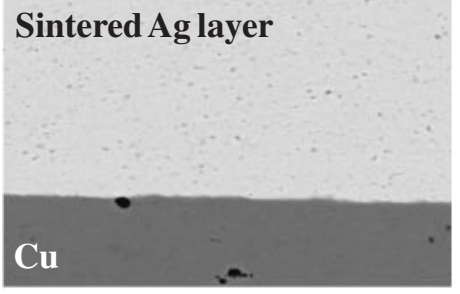

(c) At $573 \mathrm{~K}$

Fig. $7 \mathrm{BE}$ images of $\mathrm{Cu} / \mathrm{Ag}$ interface in the joints bonded at various bonding temperature for $300 \mathrm{~s}$ under bonding pressure of $5 \mathrm{MPa}$.

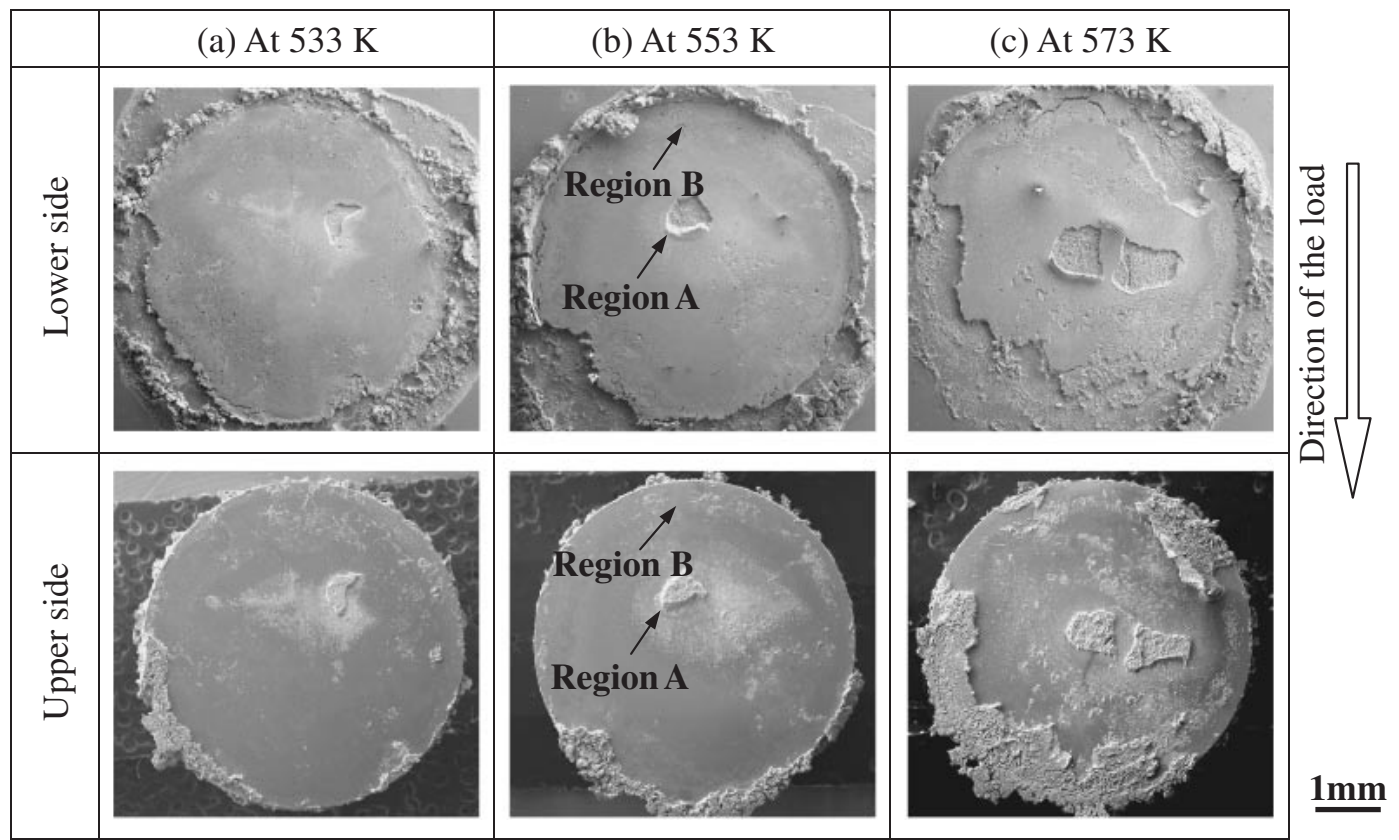

Fig. 8 SE images of fracture surfaces of $\mathrm{Cu}-$ to-Cu joints bonded at various bonding temperature for $300 \mathrm{~s}$ under bonding pressure of $1 \mathrm{MPa}$.

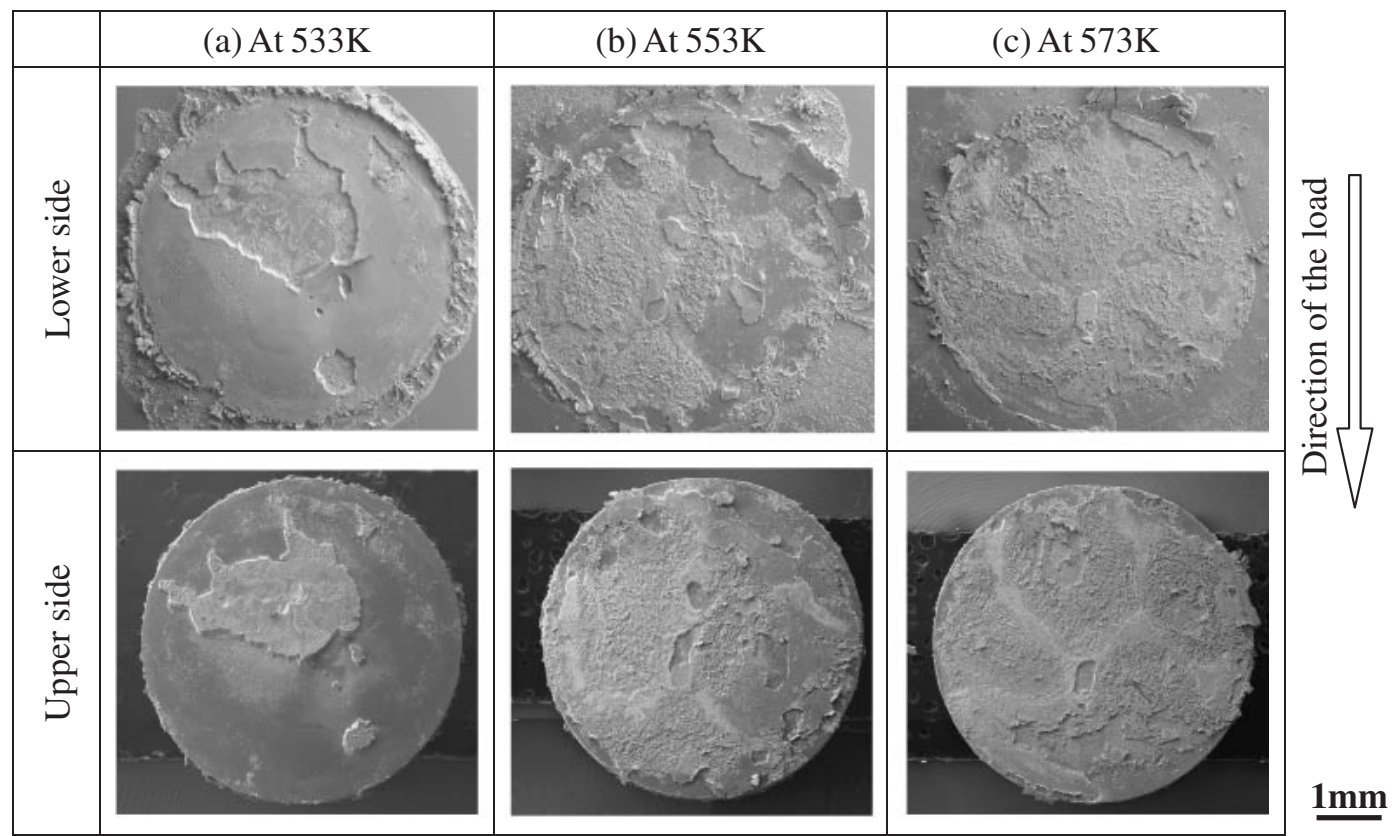

Fig. 9 SE images of fracture surfaces of $\mathrm{Cu}$-to- $\mathrm{Cu}$ joints bonded at various bonding temperature for $300 \mathrm{~s}$ under bonding pressure of $5 \mathrm{MPa}$. 


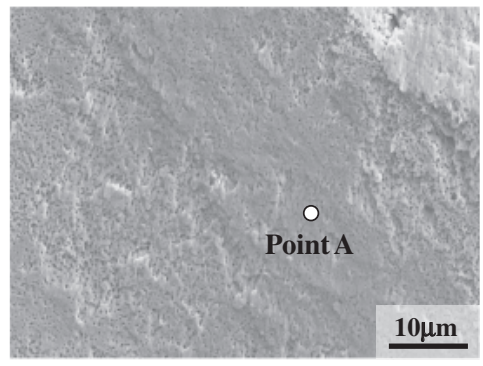

(a) Sintered Ag side (Lower side)

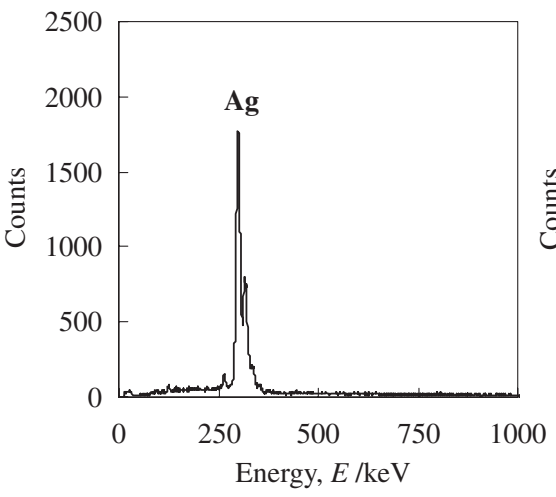

(c) Point A

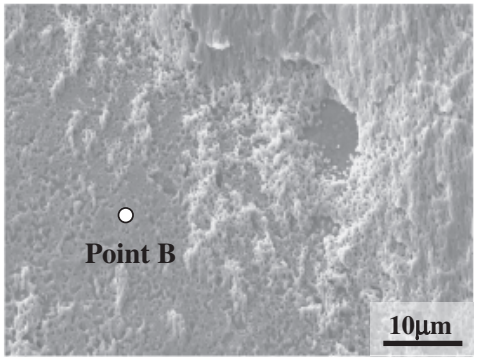

(b) $\mathrm{Cu}$ side (Upper side)

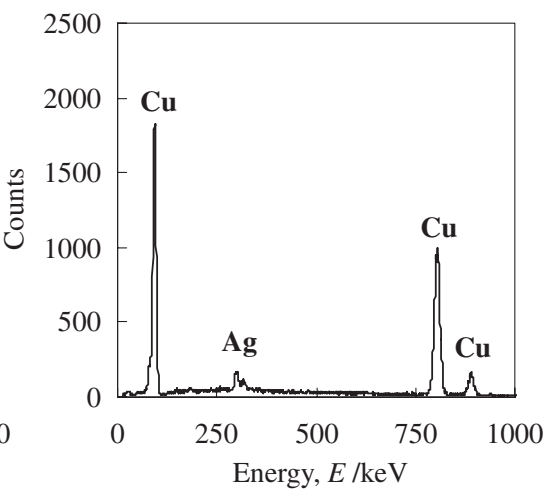

(d) Point B

Fig. 10 SE images of region A in Fig. 8(b) and EDX spectra of points A and B.

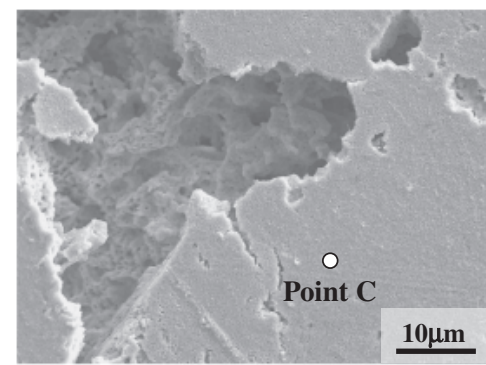

(a) Sintered Ag side (Lower side)

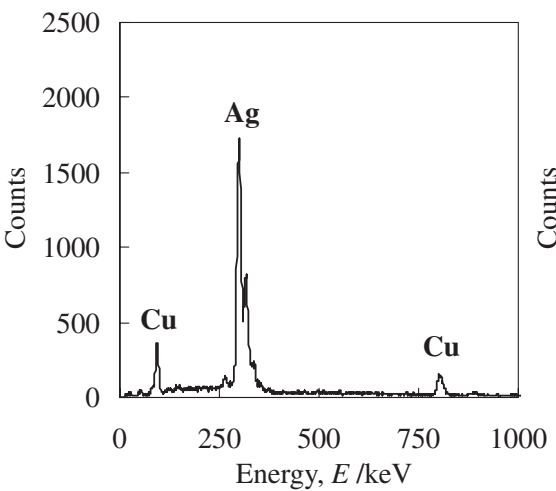

(c) Point C

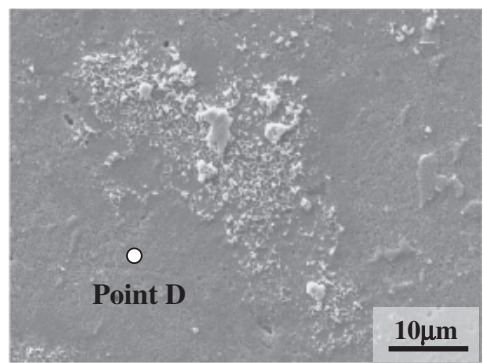

(b) $\mathrm{Cu}$ side (Upper side)

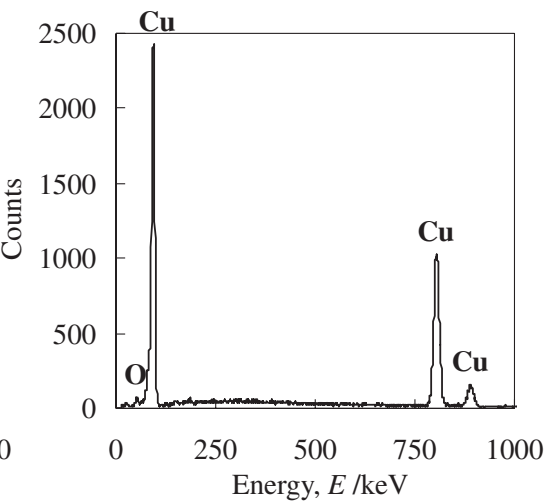

(d) Point D

Fig. 11 SE images of region B in Fig. 8(b) and EDX spectra of points C and D.

was migrated from the $\mathrm{Ag} / \mathrm{Cu}$ interfacial to the sintered $\mathrm{Ag}$ layer. These results show that both the strength of the Ag layer and the interface between $\mathrm{Ag} / \mathrm{Cu}$ were enhanced, and the $\mathrm{Ag} / \mathrm{Cu}$ interfacial strength was more than that of the sintered Ag layer under the high pressure conditions.

The influence of the bonding temperature was not recognized from the microstructure observation of the sintered Ag layer. However, the fracture morphology was affected by the bonding temperature under a pressure of $1 \mathrm{MPa}$. Figure 10 shows the higher magnification images of the region A in Fig. 8(b) and the EDX spectra of the points A and $\mathrm{B}$ respectively. Figure 11 shows the higher magnification 

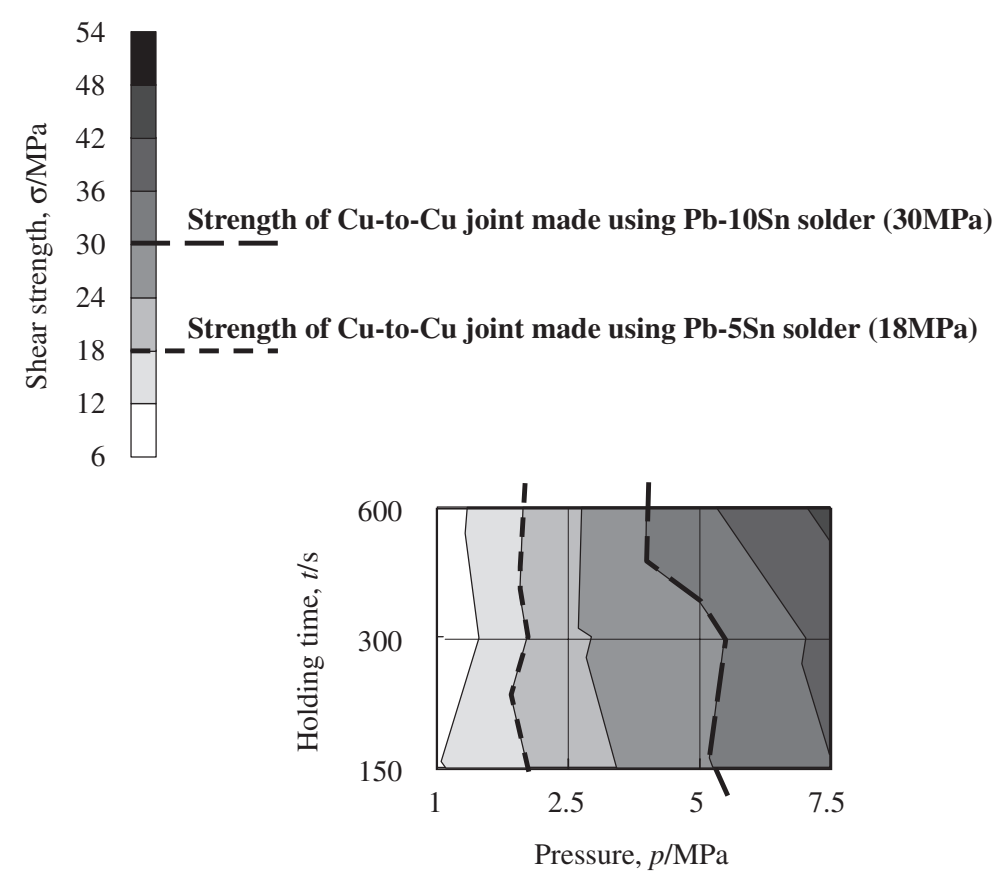

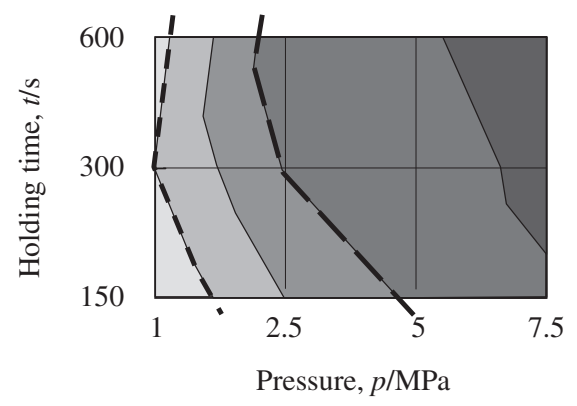

(b) At $553 \mathrm{~K}$

(a) At $533 \mathrm{~K}$

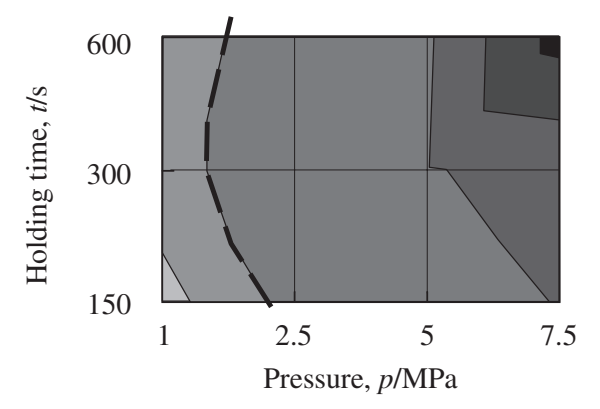

(c) At $573 \mathrm{~K}$

Fig. 12 Contour maps for shear fracture strength of the joints using Ag nanoparticles with varying pressure and holding time at each bonding temperature.

images of the region B in Fig. 8(b) and the EDX spectra of the points $\mathrm{C}$ and $\mathrm{D}$ respectively. In the region $\mathrm{A}, \mathrm{Ag}$ was detected on the $\mathrm{Cu}$ side and the fractured $\mathrm{Ag}$ layer was elongated and deformed. Therefore, the fracture was propagated within the sintered $\mathrm{Ag}$ layer around the $\mathrm{Ag} / \mathrm{Cu}$ interface. However, $\mathrm{Ag}$ was not detected on the $\mathrm{Cu}$ side and the plastic deformation was not recognized on the fractured surface in the region B (Fig. 11). It is considered that the $\mathrm{Ag} / \mathrm{Cu}$ interfacial strength in this region was not sufficient. In addition, the $\mathrm{Cu}$ detected on the sintered $\mathrm{Ag}$ side [Fig. 11(c)] might be caused by the $\mathrm{Cu}$ oxide. This suggests that the $\mathrm{Cu}$ oxide film remained and the metallurgical bonding of $\mathrm{Ag}$ to $\mathrm{Cu}$ couldn't be achieved in this region. The area of the region A declined in the fracture surface of the joint bonded at a lower temperature of $533 \mathrm{~K}$ as shown in Fig. 8(a). On the contrary, it expanded in the joint bonded at a higher temperature of $573 \mathrm{~K}$ as shown in Fig. 8(c). These results suggest that the $\mathrm{Ag} / \mathrm{Cu}$ interfacial strength was enhanced by the increase of the bonding temperature, and this effect was more significant under the low bonding pressure conditions. The increase in a bonding temperature more effectively shortens the period of the decomposition of the organic shell than that of the holding time does. It is expected that this effect improves the bondability to $\mathrm{Cu}$.

\subsection{The comparisons with the lead-rich solder joints}

Figure 12 shows the contour maps for the shear strength that were constructed from the results of Fig. 5. Two kinds of the dotted line in Fig. 12 show the strength of the $\mathrm{Cu}$-to- $\mathrm{Cu}$ joints using the $\mathrm{Pb}-5 \mathrm{Sn}$ solder and the $\mathrm{Pb}-10 \mathrm{Sn}$ solder respectively. The joints using the Ag metallo-organic nanoparticles had higher strength than those using the current lead-rich solders under wide bonding conditions. The bonding conditions that satisfy the lower basis of the joint strength for alternative to the $\mathrm{Pb}-5 \mathrm{Sn}$ solder, $18 \mathrm{MPa}$, are quite wide range including a low bonding temperature and a low bonding pressure. The rise of the bonding temperature and the increase in the bonding pressure can meet the higher basis of the joint strength for the alternative to the $\mathrm{Pb}-10 \mathrm{Sn}$ solder, $30 \mathrm{MPa}$.

\section{Conclusion}

We have proposed a novel bonding process using Ag 
metallo-organic nanoparticles, which can be alternative to that using lead-rich high melting point solders. The following results were obtained in this study:

(1) The joint strength increased only a little with increasing holding time in this bonding condition, though the accumulation in the holding time may promote the sintering of the Ag particles. This suggests that the sintering of the $\mathrm{Ag}$ is almost completed after hold time of $2.5 \mathrm{~min}$.

(2) The increase in the bonding pressure brought the significant improvement of the joint strength at each bonding conditions. In particular, this improvement is more prominent at lower bonding temperature.

(3) The increase in the bonding temperature considerably raised the joint strength under a lower bonding pressure of $2.5 \mathrm{MPa}$ or less, while the joint strength was little affected by a bonding temperature under a higher bonding pressure of $5 \mathrm{MPa}$ or more.

(4) The bonding conditions that meet the basis of the joint strength for the alternative to the conventional lead-rich solders were presented.

\section{Acknowledgement}

This research was partly supported by 'Priority Assistance of the Formation of Worldwide Renowned Centers of Research-The 21st Century COE Program (Project: Center of Excellence for Advanced Structural and Functional Materials Design)' and a Grant-in-Aid for Scientific Research Development from the Ministry of Education, Culture, Sports, Science and Technology of Japan.

\section{REFERENCES}

1) A. Hirose, H. Yanagawa, E. Ide and K. F. Kobayashi: Sci. Technol. Adv. Mater. 5 (2004) 267.

2) T. Shimizu, H. Ishikawa, I. Ohnuma and K. Ishida: J. Electro. Mater. 28 (1999) 1172.

3) J. N. Lalena, N. F. Dean and M. W. Weiser: J. Electro. Mater. 31 (2002) 1244.

4) E. Ide, S. Angata, A. Hirose and K. F. Kobayashi: Proc. of the 13th Sympo. on Microelectro. (2003) p. 96.

5) Lopes WA: Phys. Rev. E 65 (2001) 031606.

6) M. Oda: J. Jpn. Inst. Electro. Packag. 5 (2002) 523.

7) H. Nagasawa, M. Maruyama, T. Komatsu, S. Isoda and T. Kobayashi: Phys. Status Solidi 67 (2002) 191.

8) E. Ide, S. Angata, A. Hirose and K. F. Kobayashi: Acta Mater. 53 (2005) 2385.

9) Y. Ukita, K. Tateyama, M. Segawa, Y. Tojo, H. Gotoh and K. Oosako: in 38th Int. Microelectro. and Pakag. Sympo., (2004) WA7.

10) Test methods for lead-free solders-Part 5: methods for tensile tests and shear tests on solder joints, JIS Z 3198-5. 